\title{
Capabilities and application possibilities of the intelligence functional sub-system of "HUTOPCCIS"1 computer-aided command system operating on a geospatial information systems basis
}

\author{
FURJÁN Attila
}

\begin{abstract}
Operational command is to be implemented always in the area of operations, or area of responsibility, using command assets that have a direct effect on the operational activities, and are able to quickly and operatively react to changes in the situation, and to make available the necessary forces and equipment in due time corresponding to the current situation in order to support the combat activity. These requirements are met by field command systems.

This study is aimed at presenting the development results, capabilities, and application possibilities of the computer-aided intelligence planning and command and data processing functional sub-system operating on a geospatial information systems basis.

Head words: "HUTOPCCIS" command system, target intelligence, target reporting, target analysis, target data processing, digital map, geospatial information systems, intelligence planning on digital maps, visibility examination, detected targets, monitoring of the fire for effect.
\end{abstract}

\section{Introduction}

Operational, tactical leadership is a command and control system that is different from ordinary peacetime command, and its main purpose is to plan the economic and focused usage of the available capabilities, to define tasks and missions on the operational or tactical level, and to control the processes of employment.

The modern armed forces can fulfil the tasks determined at the so-called levels of ambition, the forecast tasks - in employment either under Article 5 of the North Atlantic Treaty or not - and meet the requirements of today and those set by the alliance only if they possess and apply a "Tactical Command and Control Information System" which — as an element of the automated command system of future land units - ensures the employment planning as well as the command of combat (manoeuvre), combat support, and combat service units, sub-units, forces as an element of the automated command system of future land units.

The sub-systems of the battlefield system are led on the forces level but must be independent to an appropriate extent on each independent intermediary level. Access to the

1 HUTOPCCIS — Hungarian Tactical Operational Command and Control Information System — Magyar Harcászati Hadmúveleti Vezetési és Irányítási Információs Rendszer

2 Lieutenant-Colonel, PhD., Associate Professor (Univ.), National University of Public Service, Budapest, Hungary 
data and information is controlled at every employment and command level; a lower-level command element, its office staff, departments have access only to those superior-level data and information which have been permitted and made available by the superior level for the accomplishment of the mission.

Already developed sub-systems of the "HUTOPCCIS" command system:

1. Manpower and technical establishment registry and maintenance functional sub-system;

2. Intelligence planning \& command and data processing functional sub-system;

3. All-arms (operational) functional sub-system;

4. Fire support functional sub-system;

5. Route planning and march command functional sub-system;

Developers of the computer-aided tactical command system:

- Furján Attila,

- Chief Programmer: Lepesi Györgyné.

The subject of this study is the essence and the capabilities of one of the most important sub-systems of the command system: the intelligence functional sub-system.

\section{Combat support sub-systems — intelligence functional sub-system}

\section{The purpose of the intelligence functional sub-system}

The intelligence and data processing sub-system ensures the planning and allocation of intelligence tasks, the determination of combat missions, the creation of the data base of the expected enemy and non-friendly forces, and the planning of grouping, deployment, and activities of the intelligence/reconnaissance elements in the phase of operations, combat activity, and employment of the combat (manoeuvre), combat support, and combat service units, sub-units. Through supporting all these tasks, it ensures the professional elaboration and preparation of plans, orders, sketches, documents, registries which are necessary for the commanding of operations, battles.

The sub-system allows for the collection, accurate recording, operational and tactical elaboration of the data and information gathered and reported by the elements of the unified intelligence system (combat recce, long-range recce, artillery, engineering, chemical protection, etc). On the basis of the data bases and plans created during the preparation of operations and combats, it develops comprehensive information and enables the information to be transmitted to command posts, working groups, departments.

The sub-system supports and ensures the creation and continuous maintenance of the "Intelligence Log” in both paper- and digital format.

\section{Capabilities and application possibilities of the intelligence functional sub-system:}

- it can be used in tactical and operational situations as well as in crisis management;

- to use it, professional knowledge and intermediate level PC skills are necessary;

- in processing intelligence data, matches NATO STANAG requirements; 
FURJÁN Attila: Capabilities and application possibilities of the intelligence functional sub-system...

- the DTA ${ }^{3}-50$ digital map and digital elevation model created by the Hungarian Defence Forces Geo-information Office are used as the base platform;

- provides the possibility to set different scales on the digital map and to adjust the UTM grid;

- UTM, MGRS and geographical coordinates used by NATO may be entered into and acquired from the digital maps;

- coordinate transformation for the adjacent zones in the UTM projection system is fully supported;

- distance measurement is possible on the digital map;

- height data can be acquired (through a digital elevation model);

- a raster (scanned) map can be used as a base platform;

- digital orthophoto can be used as a base platform;

- stationary and mobile target intelligence data can be entered, intelligence information can be gathered, processed, and displayed on a digital map with NATO standard symbols (in accordance with APP-6C);

- the value of the intelligence information can be defined in accordance with NATO STANAG;

- the intelligence information can be queried by selecting the symbol of the detected targets on the digital map;

- the positions, posts of the intelligence/recce forces and assets can be planned using the digital map;

- the reconnaissance capabilities and visibility can be displayed and examined from the intelligence/recce positions and posts;

- the capabilities and overall visibility of all intelligence sources can be examined;

- target zones can be displayed on the digital map (zones A, B1, B2, C, and D);

- the detected targets can be grouped by priority, listed, and printed;

- the manoeuvres and movements of the intelligence/recce forces and assets can be managed, manoeuvre estimations and calculations can be carried out;

\section{The intelligence process}

1. "The intelligence cycle is an activity during which information is acquired, gathered, and turned into intelligence data, to make those available for users.” [1: 51]

The intelligence process (cycle) includes four parts:

- control (tasking);

- acquisition of data (data gathering);

- processing;

- distribution (reporting).

\section{Control (tasking)}

The first phase of the intelligence process involves the definition of requirements by the Commander and the intelligence and operations staff. The Commander defines the basic

3 Digitális Térképészeti Adatbázis - Digital Cartographic Database 
intelligence mission and guidance, and together with the staff, carries out the planning, command and control and decision-making tasks to define the assessment of intelligence data and to ensure continuous implementation.

Intelligence data are mainly required by G2 or S2 as well as G3 or S3 officers, and the fire support coordinator officer (FSCOORD). The G2 or S2 controls intelligence data gathering and the assessment work for all data sources, and ensures that battlefield information and intelligence data are quickly distributed.

The Commander defines the so-called "Primary Intelligence Requirements" on the basis of proposals by the G2 or S2. They investigate the assigned task, the status of the enemy, terrain conditions, Commander's guidance and concept of operations (combat) so as to define the intelligence data- and information needs. The tasking so developed will contribute to the completion of the common primary goal of intelligence carried out through all intelligence/ recce forces and assets, that is: to provide the necessary intelligence data about the enemy and the terrain for ensuring foresight, drawing correct conclusions, and destroying the enemy by fire.

\section{Content and preparation of data bases}

The necessary data are prepared and refined during computer processing. The expected enemy targets are entered into the data base of "Expected and Detected Targets", taking into account their structure. (Figures 1, 2). They indicate destruction of targets in the destruction field in order of their priority, consistent with NATO requirements. As follows:

I immediately, interrupting an on-going strike if necessary;

A upon acquisition, as soon as the assets are available;

$\mathrm{P}$ as per the plan.

They clarify the enemy High Value Targets (HVT's) in the "System of Targets" data base (Figures 3, 4). The HVT's represent high value from the standpoint of the enemy, that is the forces and assets most necessary for the accomplishment of their mission. For example: if the enemy forces are preparing an attack operation (battle) in an area where several river crossings are located then those engineering assets ensuring the crossing of rivers will qualify as high value targets. 
FURJÁN Attila: Capabilities and application possibilities of the intelligence functional sub-system...

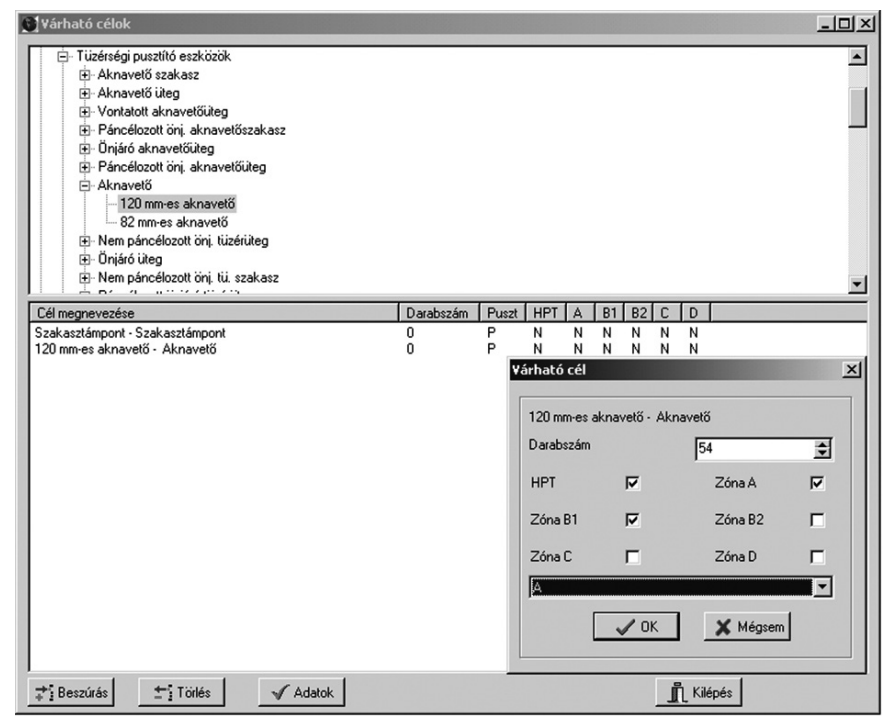

Figure 1. Data base of expected and detected targets (own resources)

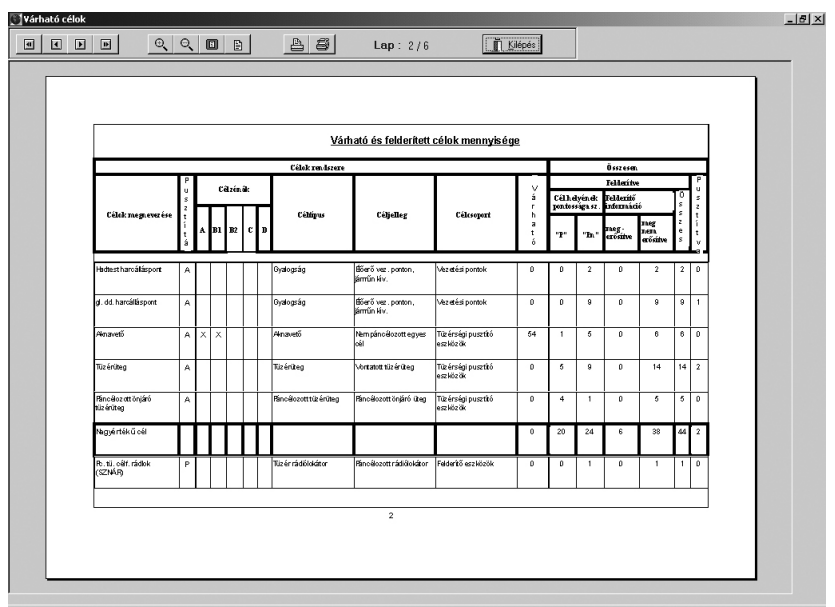

Figure 2. List of expected and detected targets (own resources)

High Value Targets (HVT's) — from which High Pay-off Targets are to be selected — include the following groups of targets:

- Weapons of mass destruction (e.g. missile platforms suitable for the delivery of weapons of mass destruction);

- Artillery weapons (artillery, multiple-barrelled launcher, and mortar batteries and platoons);

- Antiaircraft artillery (antiaircraft missile and artillery batteries and platoons);

- Command posts (observation posts of fire support and observers, automated fire and strike control centres of the artillery, command observation posts, forward command posts, communications centres, up to the first echelon brigades, command, guidance, 
FURJÁN Attila: Capabilities and application possibilities of the intelligence functional sub-system...

control, and warning centres and posts of air forces, up to brigade level);

- Intelligence and target intelligence assets, data processing centres;

- Electronic warfare (EW) assets (means of electronic recce, command posts of radio jammer battalions);

- Combat (attack) troops, reserves;

- Logistics units, logistics centres;

- Airports.

The Commander shall identify the so-called High Pay-off Targets (HPT’s). High Pay-off Targets (HPT's) are High Value Targets (HVT's), and attacking them will highly contribute to the completion of operational (tactical) aims. The G2 or S2 branch, in cooperation with the fire support officer (FSO) and other staff branches, proposes which HVTs shall be qualified as HPTs. In my opinion, the proper interpretation of these two is of utmost importance, as the so-called FM publications include translation inaccuracies, e.g. both HV and HP targets are called "high value targets" in the translation several times, which is wrong, since their English denominations are different, and their definitions are substantially different, too. The literal Hungarian translation of "High Value Target" expresses the sense of the expression. The literal Hungarian translation of "High Pay-off Target" (HPT) would mean targets that pay off, that is their destruction is of priority from the point of view of one's own forces for the completion of operational (tactical) aims. (Figure 3)

Its literal translation into Hungarian does not fit the language; therefore, it is better to nominate them "targets of high priority" in Hungarian. So, high pay-off targets (HPTs) are selected from high value targets (HVTs), that is, every high pay-off target (HPT) is also a high value target (HVT), but not every high value target (HVT) will be a high pay-off target (HPT). The decision to qualify a HVT as HPT demands careful coordination work within the staff. Only those HVTs will be qualified as HPTs, which are to be reconnoitred and struck in order to accomplish the tasks specified by the Commander.

HPTs, because of their importance, have priority in the course of specifying intelligence tasks. HPTs are to be identified both in the data base of expected and detected targets (Figure 1) and in the system of target data base (Figure 4). Thereby, the software will group HPTs separately from the rest of the reported targets during data gathering.

The needed initial data shall be entered in the first phase of the intelligence process, such as:

Name, call sign and coordinates of own intelligence/recce sub-units; - coordinates are UTM, as in NATO. The list of own forces can be printed in the form of a chart.

The data base includes the standardized symbols of all intelligence/recce assets, so they can be displayed on the digital map.

The exercise maintenance data base shall be prepared during planning, and the following data shall be entered:

- the number of target data processes; - which means the set of intelligence data to be processed in a tactical (operational) time interval. A new target data processing can be opened at any time - in accordance with the tactical situation — and the old target data processing can be saved and recalled at any time;

- the basic direction;

- the coordinates of the battlefield (width and depth);

- the beginning of the exercise. 
The targets are grouped in a logical order (main group of targets, group of targets, name of the target, type and nature of the target) in the system of target data base. The default target properties are indicated, such as coverage, size, whether it qualifies as a HPT, when its destruction is planned. Furthermore, the database can store images of the targets (installations, equipment) and their most important battle and technical data. Thereby these image and text data can be recalled and examined at any time during assessment of the targets (Figure 11). The system of targets presently includes the data of 203 targets but it can be augmented also during a battle. The data base includes the NATO standard symbols of the targets, so they can be displayed on the digital map.

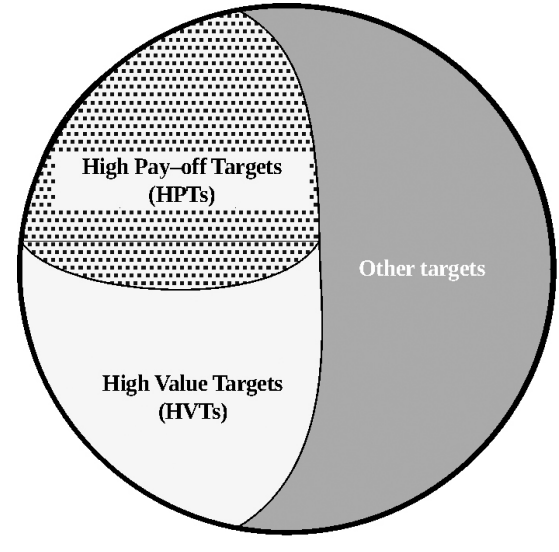

Version "A"

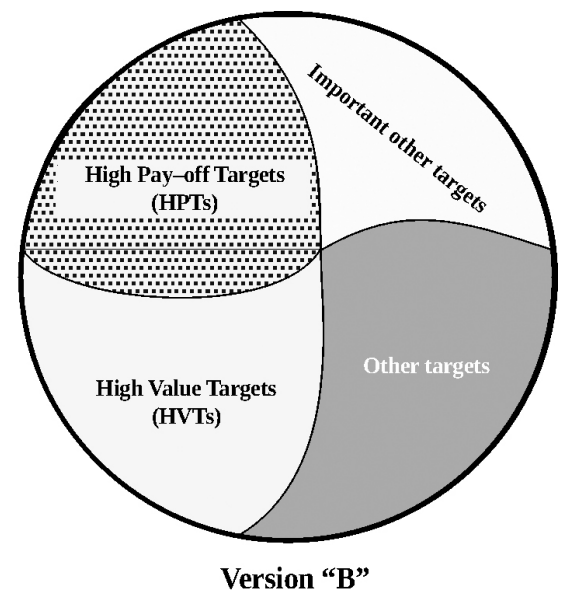

Version "B"

Figure 3. Composition of targets (own resources)

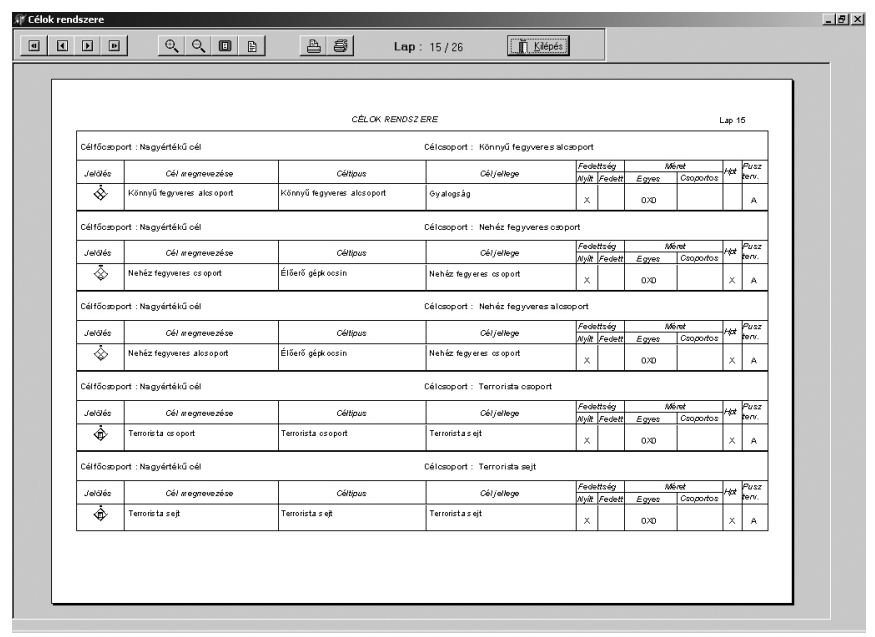

Figure 4. System of the targets data base (own resources)

Besides these, the following data bases are available:

- the actual target no. file; - from which the software provides a target no. for the targets; - The numbering of targets includes two letters and four numbers, consistent 
FURJÁN Attila: Capabilities and application possibilities of the intelligence functional sub-system...

with NATO STANAG. The first letter stands for the country, the second for the military unit (e.g. QB0801).

- maintenance of equipment; - includes the intelligence/recce assets and their properties (accuracy- and reliability properties and reconnaissance capabilities of intelligence sources and assets). The list of intelligence/recce assets can be printed in form of a chart.

The front edge is designated on the digital map in the combat preparation phase. There are two ways of its designation:

- Designing it directly on the digital map during planning;

- After assuming battle formation, artillery intelligence sub-units report the accurate coordinates of the front edge by polar or Cartesian coordinates along the front edge, with 50-100 m gaps.

The forward artillery intelligence sub-units have the obligation to continuously observe the front edge, so that in case the front edge is displaced by $500 \mathrm{~m}$ the artillery intelligence troops (fire support and fire observation groups) located at front can instantly report and submit the new front edge in form of map data, which will then be refined by the software and be visible on the digital map accordingly.

The NATO concept on target intelligence prescribes the division of the enemy's operational (tactical) areas into zones. These zones in practice include adjacent target zones. As such, the HVTs are located in these zones during the operations (battles). In the course of assessing the enemy targets, they shall find out in which zone the HVTs are expected to be located, and indicate that in the "target zones" column of the data base of expected and detected targets.

\section{Location of HPTs within the target zones}

The first zone is zone "A", in a distance of $0-5 \mathrm{~km}$ from the line of contact. The enemy's combat troops, field and anti-aircraft artillery, reconnaissance, ranging and target intelligence assets, command posts, communications centres are located in this zone.

The primary task of visual reconnaissance is to specify the HPTs in zone "A". $100 \mathrm{~mm}$ armour-piercing guns, which are usually used for direct laying but usually also capable of indirect laying, are located in this zone. The equipment of the division artillery group is situated 3-6 km deeper towards the end of zone "A". These assets include $130 \mathrm{~mm}$ guns suitable for the delivery of nuclear warheads, $152 \mathrm{~mm}$ gun-howitzers, self-propelled and motorized howitzers, $122 \mathrm{~mm}$ and $220 \mathrm{~mm}$ multiple-barrelled launchers.

These weapon systems have great destruction capabilities, posing direct danger and threat to one's own troops.

Destruction of command posts in due time is very important in the fight against the enemy's artillery. War experience has shown that a bigger part of the enemy's artillery is not able to conduct a return fire due to the neutralization and suppression of command posts, communications centres and lines. In modern circumstances, this task can be carried out more efficiently by radio electronic suppression, which does not exclude the necessity of destroying command posts by artillery means. The intelligence/recce organization types of the Hungarian Defence Forces have different forces and assets for the reconnaissance and graphic intersection of targets in zone "A". 
The company fire support and fire observation groups and combat reconnaissance troops possessing laser range-finders are able to detect targets to the full depth of zone " $\mathrm{A}$ " — dependent on the line and range of sight — and to specify the coordinates accurately (to $75 \mathrm{~m}$ accuracy). Besides the above-mentioned visual reconnaissance sub-units, the SNAR radio locator stations of the combat reconnaissance and artillery intelligence troops are also able to detect and accurately specify the position of mobile enemy targets - depending on visibility.

However, a sufficient amount of this equipment is not available, so they are not able to cover zone "A" of the combat area in full width without gaps. The reconnaissance of artillery and mortar batteries can be carried out in that depth by the sound-ranging battery in a reconnaissance width of $12 \mathrm{~km}$ and up to $20 \mathrm{~km}$ depth. It is advisable that the sound-ranging battery be employed in the area of main efforts of reconnaissance.

In night-time conditions, only those flash ranging sub-units are able conduct reconnaissance - up to $2 \mathrm{~km}$ - which are equipped with night vision devices. As for the future, it is necessary that flash ranging sub-units shall be equipped with night vision devices.

Also the combat (manoeuvre) forces located at the front edge can provide useful information on this zone, although the positioning may be inaccurate and shall be refined by additional intelligence.

It must be noted that in a situation at the threshold of war and during crisis management, the border guard patrols serving alongside the border of the country can provide the first information up to a depth of about $3 \mathrm{~km}$ from the border, with inaccurate positioning.

The second zone, zone "B1" is the strip between $5-20 \mathrm{~km}$ from the line of contact. Most of the high pay-off enemy targets, that is the artillery-, anti-aircraft artillery, mortar, multiple-barrelled launcher batteries and platoons, intelligence, ranging, target reconnaissance assets, command posts and communications centres, radio electronic devices are expected to be located here. The division artillery group is situated at the edge of zone " $\mathrm{A}$ " or at the front end of zone "B", usually at 3-6 km from the line of contact. These means include $130 \mathrm{~mm}$ guns and $152 \mathrm{~mm}$ gun-howitzers, howitzers, and multiple-barrelled launchers. The multiple-barrelled launchers stay at a covered (hidden) place until they receive fire order. Upon receiving the fire order, they will take their prepared firing position areas, deliver fire, and immediately make manoeuvers. The firing position area will be abandoned within 5-15 minutes. This system of employment is applied by tactical missiles, too.

Today, the basis of the artillery group is made up of self-propelled artillery systems, most of which (about $80 \%$ ) are armoured. These have a great manoeuvring capability, which enables them to stay in the firing positions only for the time of firing. This actually takes about 10 minutes, and even less for multiple-barrelled systems. However, there are even stricter requirements for future fire systems. The duration of stay of the sub-unit in the firing position area shall not exceed 5 minutes. Foreign military experts argue that by decreasing the duration of stay of artillery sub-units in the firing positions, a higher invulnerability can be ensured than by a technically furnished firing position.

An effective destruction of targets with great manoeuvring capability, such as self-propelled artillery sub-units, can be successful only by destroying them immediately after detection. This in turn tightens the requirements regarding intelligence/recce assets, data gathering, and data processing. These shall supply comprehensive target information including data about - besides the coordinates - the calibre and number of the guns and the size of the 
area taken by the sub-unit. These data will facilitate the selection of the forces and equipment to be involved in destroying the targets, ensure the choosing of the proper firing method, and exclude unnecessary use of forces and equipment when destroying individual (roving) guns.

Therefore, the application of long-range and accurate target detection assets is of utmost importance. Even the flash ranging sub-units that are equipped with laser rangefinders are able to support reconnaissance and firing only up to $10 \mathrm{~km}$ from the front edge, $5 \mathrm{~km}$ deep from the edge of zone "B1", that is to $1 / 3$ rd of the zone. The sound-ranging battery is able to locate the position of the enemy's mortars by graphic intersection up to - depending on calibre - 5-8 km and the artillery batteries up to 18-20 km from the deployment area. As the sound-ranging sub-unit is deployed at $3 \mathrm{~km}$ depth from one's own front edge and in a width of $8-10 \mathrm{~km}$, this complex is capable of carrying out reconnaissance only to the middle of zone "B1".

The SNAR-10 radio locator station can detect mobile targets (columns) to the depth of $23 \mathrm{~km}$ with an accuracy of $20 \mathrm{~m}$. Therefore, this asset can be used for the full depth of zone "B1". But it has its limitations. Its reconnaissance sector is limited to: 4-40 mils, and they are able to reconnoitre high pay-off targets (artillery batteries) only when they are moving or carrying out a manoeuvre.

In favourable visibility conditions, visual aerial reconnaissance is possible up to 15-20 $\mathrm{km}$. The coordinates of the target shall be specified through map-terrain synchronization, which will result in approximate accuracy or inaccuracy. In the development process of artillery systems, there is a strong tendency of further increasing the range of fire, to higher than $40 \mathrm{~km}$. That enables the location of fire positions outside the range of ground radio locators, which increases the significance of aerial reconnaissance.

It must be stated that Hungarian Defence Forces do not possess such reliable reconnaissance assets that would be able to locate the high pay-off targets, especially artillery equipment by graphic intersection in that zone. Mortars are high pay-off targets with great destruction capability and are especially difficult to detect, since they usually take firing positions in ravines, on the opposite side of mountains, in pits or gullies, on steep riverbanks, behind installations, in ruined buildings and basements, bushy areas, forest clearings, and other places where their camouflage is easy and reconnaissance is difficult. Mortar fire does not give such easily detectable signals as guns. Therefore, detecting enemy mortars is extremely difficult due to the small number of detectable signals and the great manoeuvring and camouflaging capabilities. As for artillery sub-units, their destruction is hindered due to their staying in the firing positions for an insignificant duration of time.

Guns, multiple-barrelled launchers, and mortars are most likely to be reconnoitred while they are firing. NATO reconnaissance sub-units use AN/TPQ-36 locators (up to $20 \mathrm{~km}$ ) and AN/TPQ-37, 47, ARTHUR and COBRA locators (up to 35-50 km). These locators can range the enemy artillery- and mortar batteries (platoons) very fast and accurately, and allow immediate destruction after detection. The locators work with computer processing. They detect and follow artillery- and mortar shells in flight. The data acquired by following the shell path is used to determine the trajectory, which allows for the estimation of the position of the weapon or the impact point. The locator operator can send the data in the required form, digitized to the supported fire control centre, and store them in the locator's memory, or delete them if the situation demands. These assets are radiation emitters and therefore exposed to electronic warfare. 
The equipment of the army artillery group is also situated in zone "B1", at a distance of about 4-12 km from the line of contact. The army artillery group involves tube fire means and heavy mortars.

Zone "B2" is situated $20-40 \mathrm{~km}$ from the line of contact. This zone is probably taken by enemy tactical- and antiaircraft missiles, the division command post, anti-aircraft defence centres, supply and logistics centres and the second echelon of combat troops (reserves). Targets in this zone represent very high value, and — mainly the tactical missiles — pose significant danger to own troops.

The reconnaissance sub-units of the Hungarian Defence Forces presently do not possess such intelligence/recce assets that would enable them to detect high pay-off targets in this zone. Similarly, — due to the firing range — our artillery is not capable of destroying targets in that zone, therefore, this mission would devolve upon the air force if the reconnaissance issue was solved. It is highly necessary to introduce long-range artillery — primarily multiple-barrelled - equipment.

Promising is the fact that the HDF are developing an unmanned reconnaissance aircraft, which would ensure continuous reconnaissance and fire support in full tactical depth. The advantage of the system lies in the fact that the data processing centre would receive information about enemy targets simultaneously with reconnoitring, and also the results of destruction by fire could be directly and reliably specified. It is also very important that radio locators for the detection of artillery equipment be introduced within the artillery organization, which would provide the capability to reconnoitre high pay-off targets in zones "B1" and "B2" and support firing at these targets.

Zone "C" is at $40-60 \mathrm{~km}$ from the line of contact, and this is where the reserve (2nd echelon) of the enemy is situated in their quartering area. Information about these targets can be gathered mainly from intelligence sources, and their destruction would only be possible by the air force.

Zone " $\mathrm{D}$ " is the area $60-150 \mathrm{~km}$ from the line of contact, and expectably the enemy operational-, antiaircraft missiles, command posts and communications centres, airports, logistics units, supply centres and storehouses are located there. Any target information about this zone can be obtained through intelligence channels, and their destruction would only be possible by the air force.

Scientific investigations by Western and Russian military scientists have shown that fighting high pay-off targets, especially artillery equipment of great destruction in the modern circumstances can only bring success if the time elapsed between the detection of the target and firing is less than 1 minute. This can be achieved only by the comprehensive integration of intelligence/reconnaissance and destruction assets; full automation of intelligence data gathering, processing, and transmitting to firing means; and rational allocation of zones of reconnaissance, zones of destroying by artillery, and zones of radio electronic suppression.

These target zones are also indicated on the digital map, paving the way for professional tasking with regards to high pay-off targets.

\section{Acquisition of data (data collection)}

As per the NATO definition, data collection is defined as: "In the sense of intelligence, it is a step of the processing phase of the intelligence cycle, during which the registry of events is 
developed by grouping the correlated pieces of information and intelligence data, facilitating further processing.” [2: 47]

In accordance with NATO principles, the intelligence data are collected from different sources. This information is immediately processed in order to provide the target data necessary for tactical decisions. In order that the Commander can make full use of the fire power under his command, an efficient intelligence data collection shall be developed. The primary conditions of successful collection of intelligence data are continuous planning and systematic coordination of the collection activity.

So to use the intelligence sources, forces, and assets involved in the data collection as effectively as possible, their employment possibilities, capabilities, and limitations shall be well known to the people controlling target intelligence.

Through computer processing, users can enter the accurate coordinates and intelligence/ recce capabilities of the intelligence forces (assets) of any units (brigade, division) into the data base. The application of the digital map facilitates proper data gathering.

"The digital map is the product of a map production technology fully based on computer support - source analysis, data collection, editing, updating, storage, electronic and reproduction outputs - which will be closely connected with a topologically uniform digital data base, and therefore will be able to convey all cartographic elements and property data necessary for the production of paper, film, and digital products which can be assigned to the 2D or 3D digital information.” [3: 223]

The "digital elevation model” (DDM) facilitates the proper planning of intelligence forces and assets on the digital map. The digital elevation model of Hungary is stored on 3 CDs. With the DDM, the terrain can be modelled, and visibility can be quickly and properly implemented by placing a vector or raster digital map on the map model, and so the location of intelligence assets can be properly and quickly planned in the phase of operation (combat activity) preparation and implementation (Figure 5). With the DDM, the uncovered areas can be quickly and accurately specified and assigned to those reconnaissance forces that are able to reconnoitre them (e.g. aerial reconnaissance).

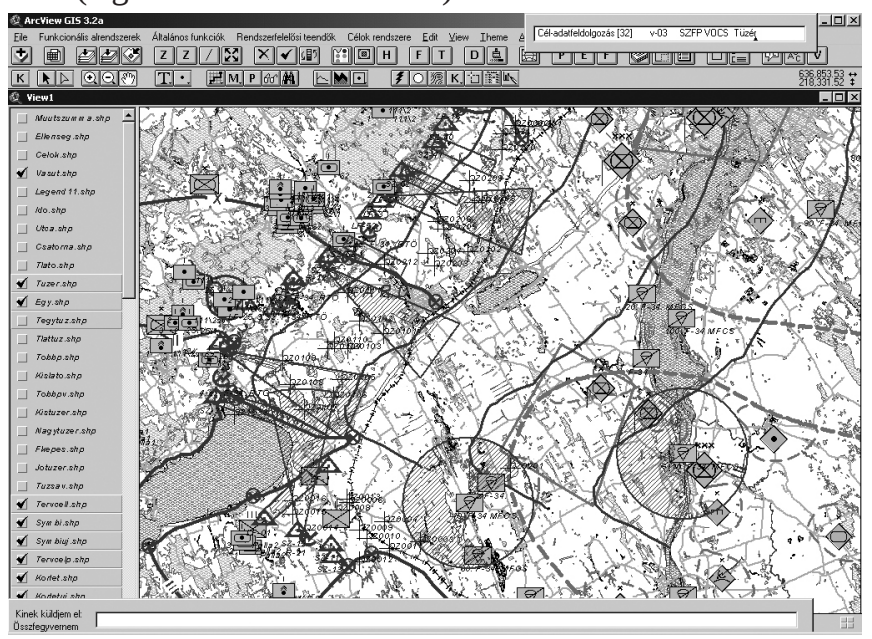

Figure 5: Reconnaissance capabilities and visibility examination of reconnaissance assets on a digital map (own resources) 
FURJÁN Attila: Capabilities and application possibilities of the intelligence functional sub-system...

\section{Conclusion}

The strategic direction specified by the General Staff and the National Public Service University has priority in the scientific and educational activities of our institute, for the work of the teachers and researchers of the faculty. The Faculty carries out its education- and scientific tasks in that spirit. One of our priorities is to research the employment possibilities of military forces engaged in combat, in asymmetric warfare, and the supporting of command and control by means of computer networks and systems.

\section{References}

[1] Intelligence Doctrine. Budapest: General Staff Euro-Atlantic Integration Work Group, 1996.

[2] Intelligence Doctrine. Budapest General Staff Euro-Atlantic Integration Work Group, 1996.

[3] Military Cartography Studies I. Budapest: ZMNE, 1997. 